\title{
The Temporal and Spatial Distribution of Hazy Days in Cities of Jiangsu Province China and an Analysis of Its Causes
}

\author{
Jiansu Wei, ${ }^{1,2}$ Weijun Zhu, ${ }^{1}$ Duanyang Liu, ${ }^{2}$ and Xiao Han $^{3}$ \\ ${ }^{1}$ Nanjing University of Information Science \& Technology, Nanjing 210044, China \\ ${ }^{2}$ Jiangsu Meteorological Observatory, Nanjing 210008, China \\ ${ }^{3}$ Suzhou Meteorological Observatory of Jiangsu Province, Suzhou 215131, China
}

Correspondence should be addressed to Weijun Zhu; weijun@nuist.edu.cn

Received 25 December 2015; Accepted 21 February 2016

Academic Editor: Herminia García Mozo

Copyright (C) 2016 Jiansu Wei et al. This is an open access article distributed under the Creative Commons Attribution License, which permits unrestricted use, distribution, and reproduction in any medium, provided the original work is properly cited.

\begin{abstract}
Based on the surface meteorological data of Jiangsu Province during 1980-2012, the climatic characteristics and the trends of haze were analyzed. The results indicated that during 1980-2012 haze days increased; in particular, severe and moderate haze days significantly increased. In the northern and coastal cities of Jiangsu Province China, haze days showed a significant increase. Haze often appeared in fall and winter and rarely in summer in the study area. It also occurred more often inland, and less along the coast. Haze occurred more often in June due to straw burning in the harvest time. The haze day increased during the 1990s over southern and southwestern Jiangsu Province; in central and northern Jiangsu, haze day increased after 2000. The continuous, regional, and regional continuous haze days all showed increasing trends. As the urban area expanded each year, industrial emissions, coal consumption, and car ownership increased accordingly, resulting in regional temperature increase and relative humidity decrease, which formed the urban heat island and dry island effects. Hence, haze formation and maintenance conditions became more favorable for more haze days, which led to the increase of haze days, and the significant increases of continuous, regional, and regional continuous haze days.
\end{abstract}

\section{Introduction}

Haze is also called gray haze [1]. According to the China Meteorological Administration (CMA) standards for haze observation and prediction [2] (2010), haze is defined as a turbidity phenomenon with many very small dry dust particles floating in the air, causing visibility to be less than $10 \mathrm{~km}$. Haze makes distant bright objects appear yellow and red and makes dark objects blue. The causes of haze are complex [3]. The aerosols in haze, besides reducing visibility $[4,5]$, contain a lot of poisonous and harmful particles [6-10], can endanger human health, and cause respiratory and cerebrovascular diseases [11].

Many domestic and foreign researchers have carried out research on the climate characteristics of haze [12-20]. Gao [12] suggested that the spatial distributions of haze in China in terms of annual and seasonal means showed more haze in the east and less in the west, and the haze days were significantly increased over the years. Yu et al. [13] studied the climate characteristics of haze days in 1971-2010 and found that haze was mainly concentrated in North China, Henan, the Pearl River Delta (PRD), and the Yangtze River Delta. Eastern China [16, 21-24], the Beijing-Tianjin-Hebei region [25-27], and the PRD region [28-32] experienced rapid economic development, so their urbanization was more advanced, and these regions suffered the most serious atmospheric pollutions as a result. Zhang et al. [33] found that Europe experienced the decline of low visibility weathers (e.g., fog, mist, and haze) over the past 30 years (1980-2009), consistent with the falling of sulfur dioxide emissions, which illustrates the significant contribution of reduced emissions to improved air quality.

With the rapid economic development and urbanization, the climate characteristics in Jiangsu Province showed great changes in recent years, in terms of frequent severe or extreme weathers, including haze [34, 35]. Yuqing et al. [36] and Tong et al. [37] analyzed the climate characteristics of haze and its influence factors in the Nanjing area. Since the abovementioned research was based on haze weather records by 
observers (not by instruments), it lacked scientific standards. In addition, there were no analyses on the continuous and regional characteristics of haze and no haze correlation. This study is based on the CMA standards for haze observation and prediction [2] (2010), with some revision, to show the climate characteristics of haze days in Jiangsu Province in recent years, including the reconstruction of haze days in the cities of Jiangsu Province, their climate characteristics, haze, time, and space distribution characteristics. By using statistical data of economic development and pollutant emission data, we analyze the causes for the changes of haze days.

\section{Data and Method}

2.1. Data. In this study, we selected observation data from the national benchmark or basic weather stations in 13 provincial-level cities in Jiangsu Province and examined meteorological factors, including weather phenomena, visibility, relative humidity, temperature, and rainfall at 08:00, 14:00, and 20:00, over the 33 years from 1980 to 2012 . Of the 13 stations, the Suzhou station was moved in 1994; the Changzhou station was moved in 1999; the Huaian station was moved in 2001; the Yancheng station was moved in 2003; the Nanjing, Nantong, and Wuxi stations were moved in 2008; and the Lianyungang station was moved in 2010. Comparison and validation show that the data are consistent and continuous before and after the stations were moved.

In this study, we also used data from the Statistical Yearbook of Jiangsu Province from 1994 to 2011, which mainly include data on economic development, such as the fully developed area, amount of coal combustion, amount of industrial emission, and number of private cars owned.

In this study, we also used data of regional atmospheric pollutants between 1980 and 2008, provided by the Atmospheric Research Database of the European Commission, which covers the area from $116^{\circ} \mathrm{E}$ to $122^{\circ} \mathrm{E}$ and $30^{\circ} \mathrm{N}$ to $3.5^{\circ} \mathrm{N}$. In this study, we used 10 years as one decade and calculated statistics on the regional distributions of the average decadal emissions of $\mathrm{NO}_{x}, \mathrm{SO}_{2}$, and $\mathrm{PM}_{10}$.

2.2. Analysis Method. At present, there are different definitions for haze, and many researchers use different criteria in their studies of haze. In this paper, we use a modified version of the method described by $\mathrm{Wu}[38,39]$ and selected daily meteorological data from 1980 to 2012 to determine the visibility and relative humidity at 08:00, 14:00, and 20:00. A day is considered hazy day when the visibility is $<10 \mathrm{~km}$ and the relatively humidity is <90; other events (such as rainfall, snow, snow storm, sand dust, dust storm, dust, and smoke) that can cause low visibility are excluded. Based on visibility (vis), we classified haze into four grades (Chinese Meteorological Administration, 2010); namely, the haze is considered light if $5 \mathrm{~km} \leq$ vis $<10 \mathrm{~km}$, mild if $3 \mathrm{~km} \leq$ vis $<$ $5 \mathrm{~km}$, moderate if $2 \mathrm{~km} \leq$ vis $<3 \mathrm{~km}$, and heavy if vis $<2 \mathrm{~km}$.

To study the regional characteristics of haze, we used the method in Zhou et al. [40] to determine the regional distribution of heavy fog and selected eight cities that are south of the Huaihe River. When haze appeared at three adjacent
TABLE 1: Decadal change of haze/d $(\text { per } \cdot \text { station })^{-1}$.

\begin{tabular}{lccc}
\hline Year & Heavy haze & Moderate & Hazy day \\
\hline $1980 \mathrm{~s}$ & 3.8 & 5.4 & 100.3 \\
$1990 \mathrm{~s}$ & 4.8 & 6.9 & 94.4 \\
$2000 \mathrm{~s}$ & 6.1 & 9.9 & 115.2 \\
$2010-2012$ & 6.3 & 8.9 & 122.4 \\
\hline
\end{tabular}

stations in one day and covered three provincial-level cities, it is considered as regional haze. Because the influence of haze is relatively significant when the visibility is below $5 \mathrm{~km}$, the visibility of regional haze is considered when it was below $5 \mathrm{~km}$ in this paper. As for continuous regional haze, we selected the number of hazy days when there were three or more hazy days at three or more stations as one continuous regional haze event.

\section{Characteristics of Spatial and Temporal Distribution of Hazy Days}

3.1. Interannual and Decadal Variation. Based on the characteristics of the variation and regional differences in the number of hazy days, we divided the 13 cities in Jiangsu Province into four regions: southern (Suzhou, Wuxi, and Changzhou), coastal (Lianyungang, Yancheng, and Nantong), southwestern (Zhenjiang, Yangzhou, Taizhou, and Nanjing), and northern (Xuzhou, Huaian, and Suqian) (Figure 2).

Since the 1980s, the number of hazy days in the province generally exhibited an upward trend, and the number of heavy and moderate hazy days also exhibited upward trends (Table 1).

From the perspective of regional distribution, the number of hazy days was less than $80 \mathrm{~d}$ in the cities of central Jiangsu during the 1980s and exceeded $110 \mathrm{~d}$ in the cities in northern and southern Jiangsu during the same period. In the 1990s, the number of hazy days declined in the three coastal cities, while the number of hazy days increased to different extents in southern Jiangsu and along the Yangtze River. In particular, the increase was the fastest in Nanjing, where the number of hazy days reached $154 \mathrm{~d}$. After the 1990s, the increase in the number of hazy days was relatively faster in northern Jiangsu, and the variation in the number of hazy days in southwestern and southern Jiangsu was not significant (Figure 1).

For the three cities in southern Jiangsu, the number of hazy days essentially remained in the range from 90 to $150 \mathrm{~d}$ after 1980, and the variation was not significant in the 33 years; the number of hazy days during the 33 years also remained essentially constant for the four cities in southwestern Jiangsu; for the three coastal cities, the number of hazy days reached its minima before and after 1995 and then began to increase after 1997, and the number of hazy days reached its highest level in the last three years of the study period; for the three cities in northern Jiangsu, the number of hazy days was approximately $100 \mathrm{~d}$ after 1980, declined to approximately 90 $\mathrm{d}$ after 1990 and exhibited an upward trend similar to that in the three coastal cities after 2000 . 

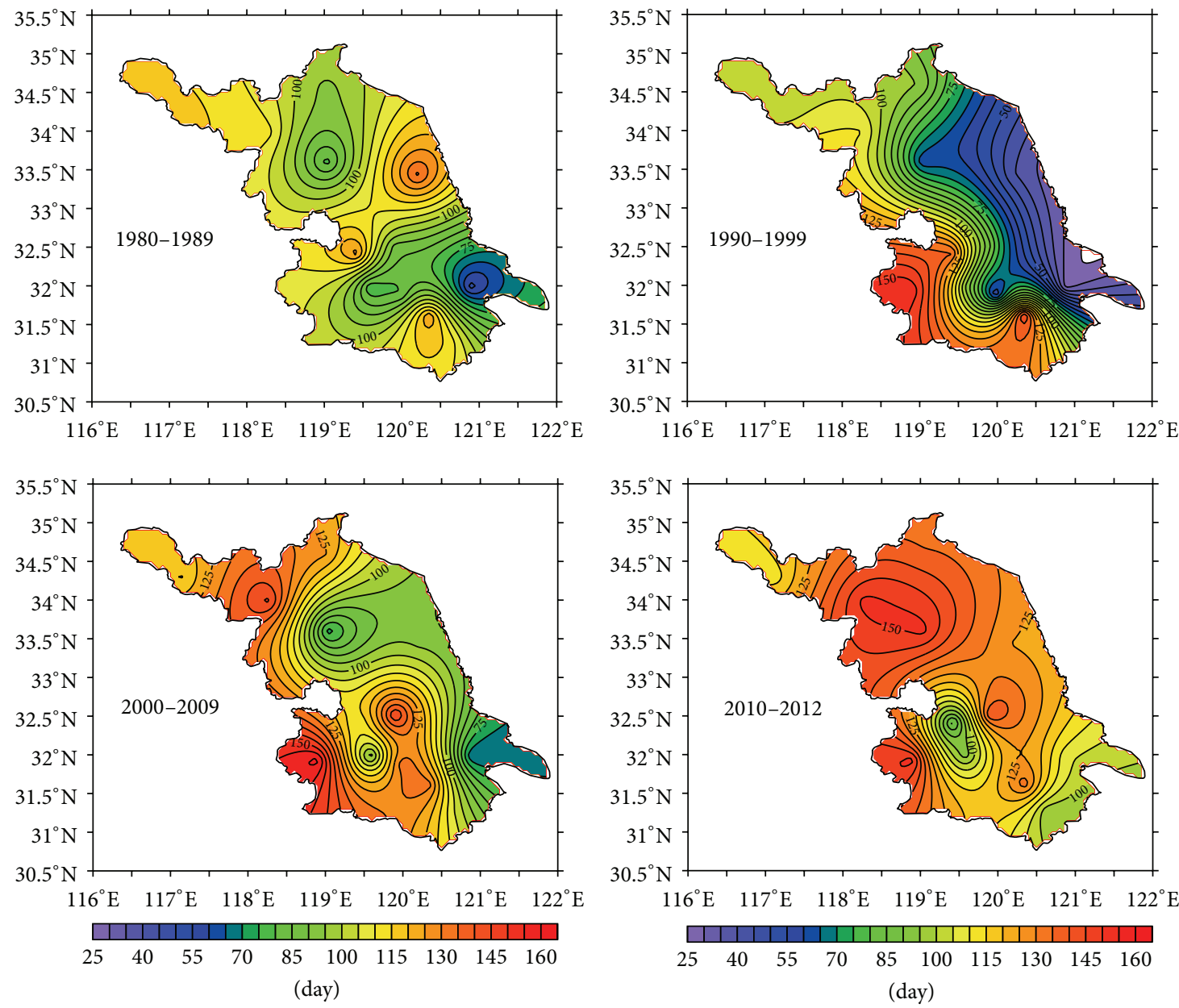

Figure 1: Space-time distribution of hazy day from 1980 to 2012 (yearly average).

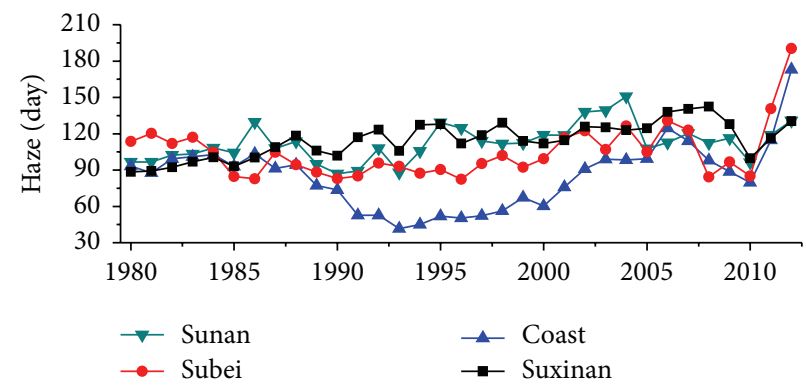

Figure 2: Temporal variability on hazy day in a year.

3.2. Seasonal and Monthly Variation. Haze had significant seasonal features in the province (Table 2). The number of hazy days was relatively high in fall (from September to November) and winter (from December to February of the following year), and the difference between the two seasons was not significant, with the number of hazy days being $393.8 \mathrm{~d}$ in both seasons. The number of hazy days was relatively low in spring (from March to May) and summer (from June to August), being approximately 305 and 273.1 d, respectively. The numbers of heavy and moderate hazy days were about 18 and $30 \mathrm{~d}$, respectively. Besides this seasonal feature, there were also regional differences (Figure 3), but it was essentially relatively high in the south and northwest, and low along the coast.

As for the monthly variation in the number of hazy days in the 13 cities (Figure 4), the number of hazy days was relatively high from October to January. In particular, there were relatively more hazy days in Wuxi, Suzhou, Nanjing, Taizhou, Yangzhou, Xuzhou, and Suqian. The number of hazy days was the lowest in July and August. In all the cities except for Suzhou, Wuxi, and Changzhou, there was a peak in the number of hazy days during June. This was mainly because 

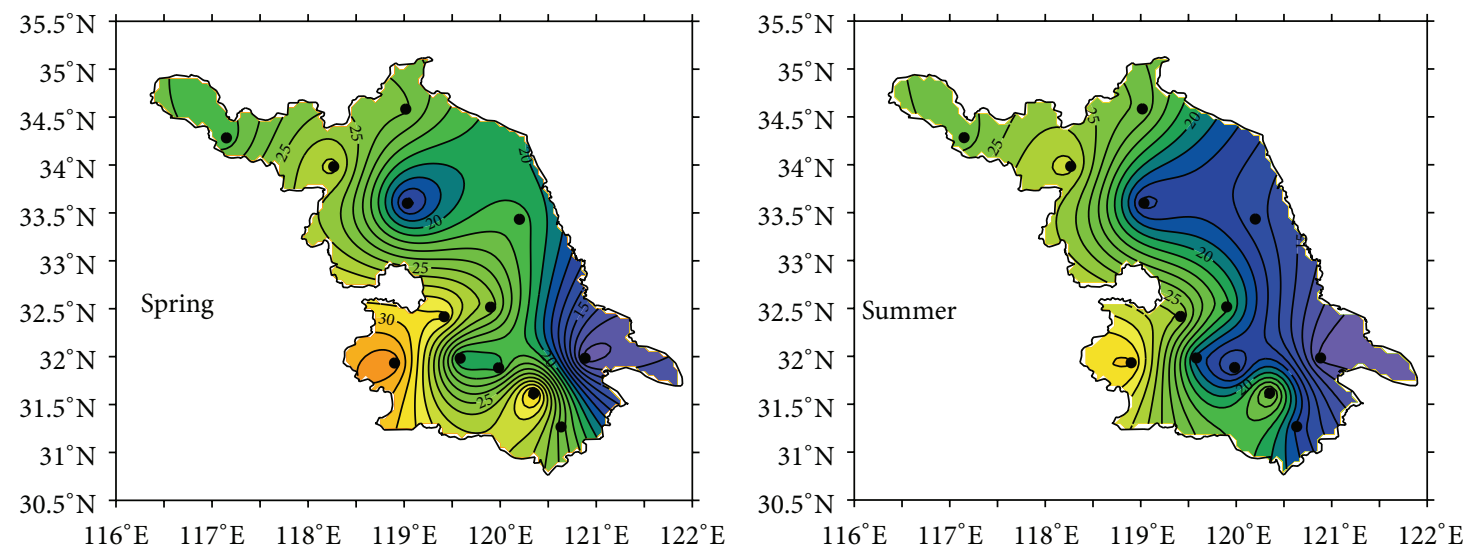

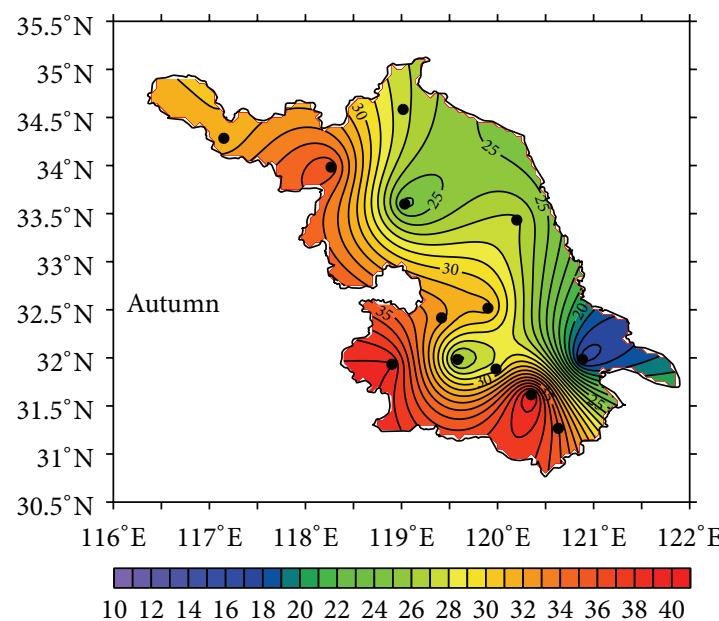

(day)

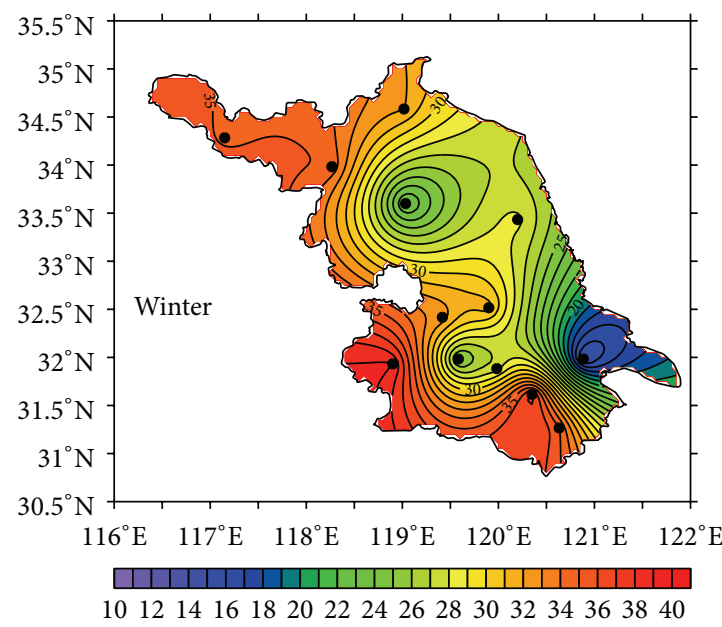

(day)

FIgURE 3: Spatial distribution of hazy day in four seasons during 1980 and 2012 (yearly average).

TABLE 2: Seasonal change of haze/d.year ${ }^{-1}$.

\begin{tabular}{lccc}
\hline Season & Heavy haze & Moderate & Hazy day \\
\hline Spring & 9.2 & 15.7 & 305.0 \\
Summer & 9.3 & 16.4 & 273.1 \\
Autumn & 17.9 & 29.8 & 393.8 \\
Winter & 18.4 & 31.3 & 393.8 \\
\hline
\end{tabular}

June was the summer harvesting and sowing season and the pollution generated by burning straws caused the air quality to deteriorate, forming haze.

3.3. Characteristics of Temporal and Spatial Distribution of Continuous Haze. In addition to correlation with economic development, the length of a sustained haze event and the number of hazy days were correlated (Table 3). From 1980 to 2012, there were a total of 5105 continuous haze events that lasted for three or more days in the 13 cities, 310 continuous haze events that lasted for more than $8 \mathrm{~d}$ in the province, and 56 continuous haze events that lasted for more than $12 \mathrm{~d}$. In particular, there was one continuous haze event that lasted for
TABLE 3: Distribution of continuous hazy day (time).

\begin{tabular}{lccccc}
\hline $\begin{array}{l}\text { Day } \\
\text { City }\end{array}$ & $3-7 \mathrm{~d}$ & $>8 \mathrm{~d}$ & $>12 \mathrm{~d}$ & $>3 \mathrm{~d}$ & $\begin{array}{c}\text { Hazy } \\
\text { day }\end{array}$ \\
\hline Nantong & 137 & 6 & 1 & 143 & 1785 \\
Zhenjiang & 262 & 7 & 2 & 269 & 2915 \\
Huaian & 209 & 11 & 3 & 220 & 2576 \\
Lianyungang & 490 & 14 & 4 & 504 & 3542 \\
Xuzhou & 367 & 16 & 3 & 383 & 3655 \\
Yancheng & 312 & 21 & 4 & 333 & 3085 \\
Changzhou & 299 & 22 & 4 & 321 & 3041 \\
Yangzhou & 458 & 22 & 0 & 480 & 3966 \\
Taizhou & 403 & 22 & 2 & 425 & 3626 \\
Suzhou & 402 & 31 & 5 & 433 & 3673 \\
Suqian & 449 & 36 & 9 & 484 & 4137 \\
Wuxi & 490 & 45 & 7 & 535 & 4413 \\
Nanjing & 526 & 48 & 12 & 574 & 4653 \\
All & 4804 & 301 & 56 & 5104 & 45067 \\
\hline
\end{tabular}

more than 20 d in Huaian, Suqian, and Nanjing. The distribution of continuous hazy days was positively correlated with 

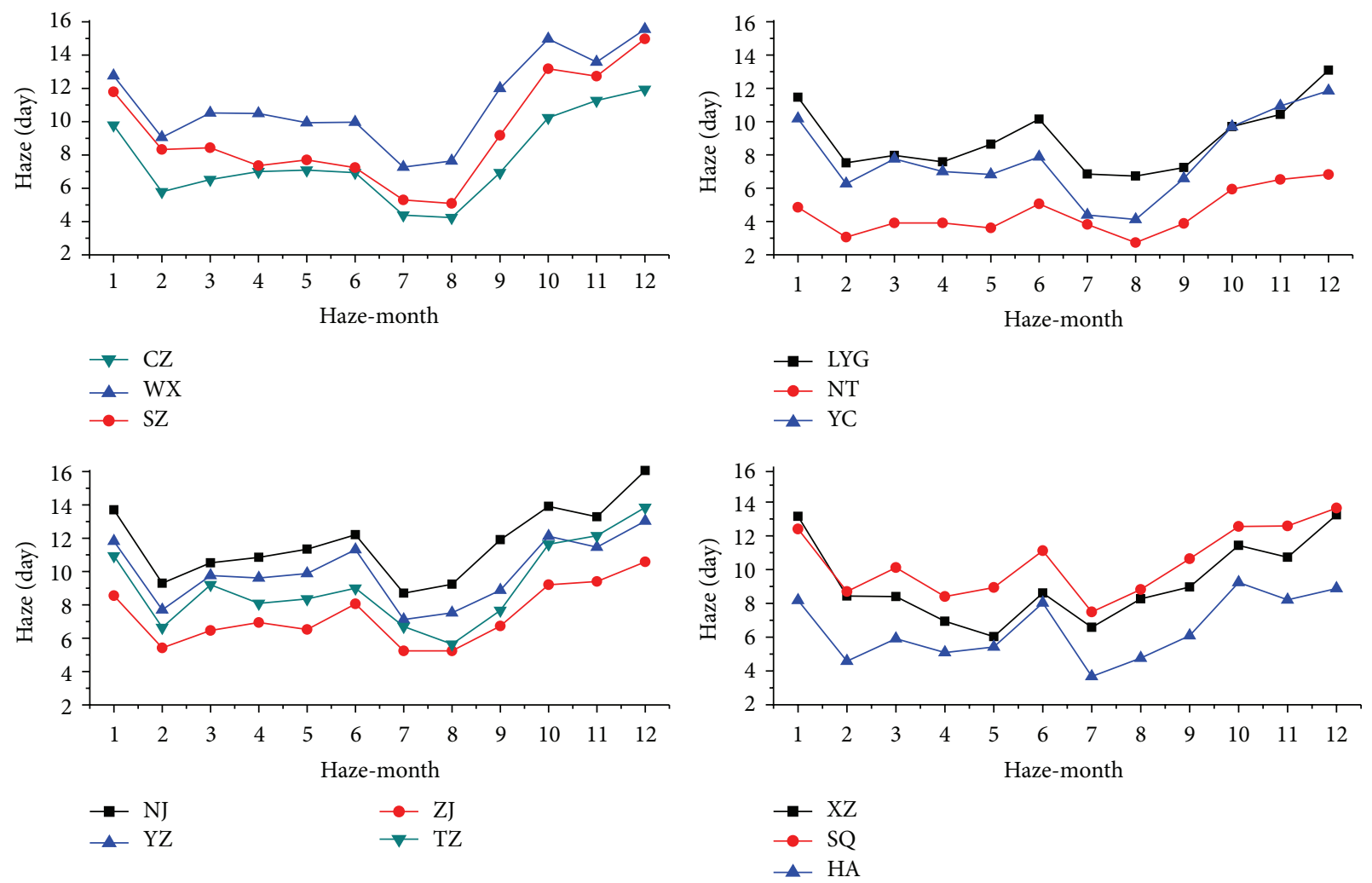

FIGURE 4: Monthly changes of hazy day during 1980 and 2012 (yearly average).

the distribution of hazy days, and in the cities with higher numbers of hazy days, there were also relatively higher numbers of continuous hazy days. Figure 5 shows a comparison of data from the stations in Taizhou and Nanjing and an analysis of the interannual variation in the number of hazy days and continuous hazy days in one year. It can be seen that the number of continuous hazy days lasting for more than three days is positively correlated with the number of hazy days.

Not only did the number of continuous hazy days increase, but the number of regional haze events also gradually increased year by year (Figure 6). Because the influence of haze is relatively more significant when the visibility is below $5 \mathrm{~km}$, in this section we select the haze events that reduced the visibility to below $5 \mathrm{~km}$. The number of regional hazy days was relatively small in the 1980s, and the number of hazy days was between 10 and $20 \mathrm{~d}$; the number of regional hazy days increased in the 1990s, and the number of hazy days was generally between 20 and $30 \mathrm{~d}$; the number of regional hazy days increased relatively quickly in the 2000s, when it was more than $30 \mathrm{~d}$ in most cities (in particular, it was the greatest in Taizhou, which experienced regional hazy days for $542 \mathrm{~d}$ ). The hazy day in all cities remained approximately $30 \mathrm{~d}$ from 2010 to 2012.

Figure 7 shows the characteristic monthly variation in the number of regional hazy days in the eight cities that are south of the Huaihe River. For the four cities in the west (Nanjing, Zhenjiang, Yangzhou, and Taizhou), the number of regional hazy days was the highest in January, June, and from October to December, and for the four cities in the east (Changzhou, Wuxi, Suzhou, and Nantong), it was relatively high only from October to December. The relatively high number of regional hazy days in the western cities during June was closely related to the burning of straws during summer harvesting and sowing season.

3.4. Continuous Features of Regional Haze. In Section 3.3, we discussed the continuous and regional features of haze in different cities when the visibility was below $5 \mathrm{~km}$. Here, we discuss the regional features of continuous haze in the eight cities that are south of the Huaihe River when the visibility was below $5 \mathrm{~km}$. Similarly, we selected the haze events that lasted for more than three consecutive days at more than three stations. From Table 4, we can see that between 1980 and 2012 more than three stations reported up to 71 regional haze events that continued for three days, up to 31 regional haze events that continued for four days, and 11 regional haze events that continued for more than five days. There were twelve regional haze events that continued for more than 6-11 days in the area south of the Huaihe River, and many stations reported regional haze events that continued for more than $6 \mathrm{~d}$, especially in southern Jiangsu.

From the analysis in Table 4, we can see that a continuous haze event that lasted for many days had very strong regional features. Moreover, continuous regional haze events that lasted for many days almost exclusively appeared between October and February of the following year. 

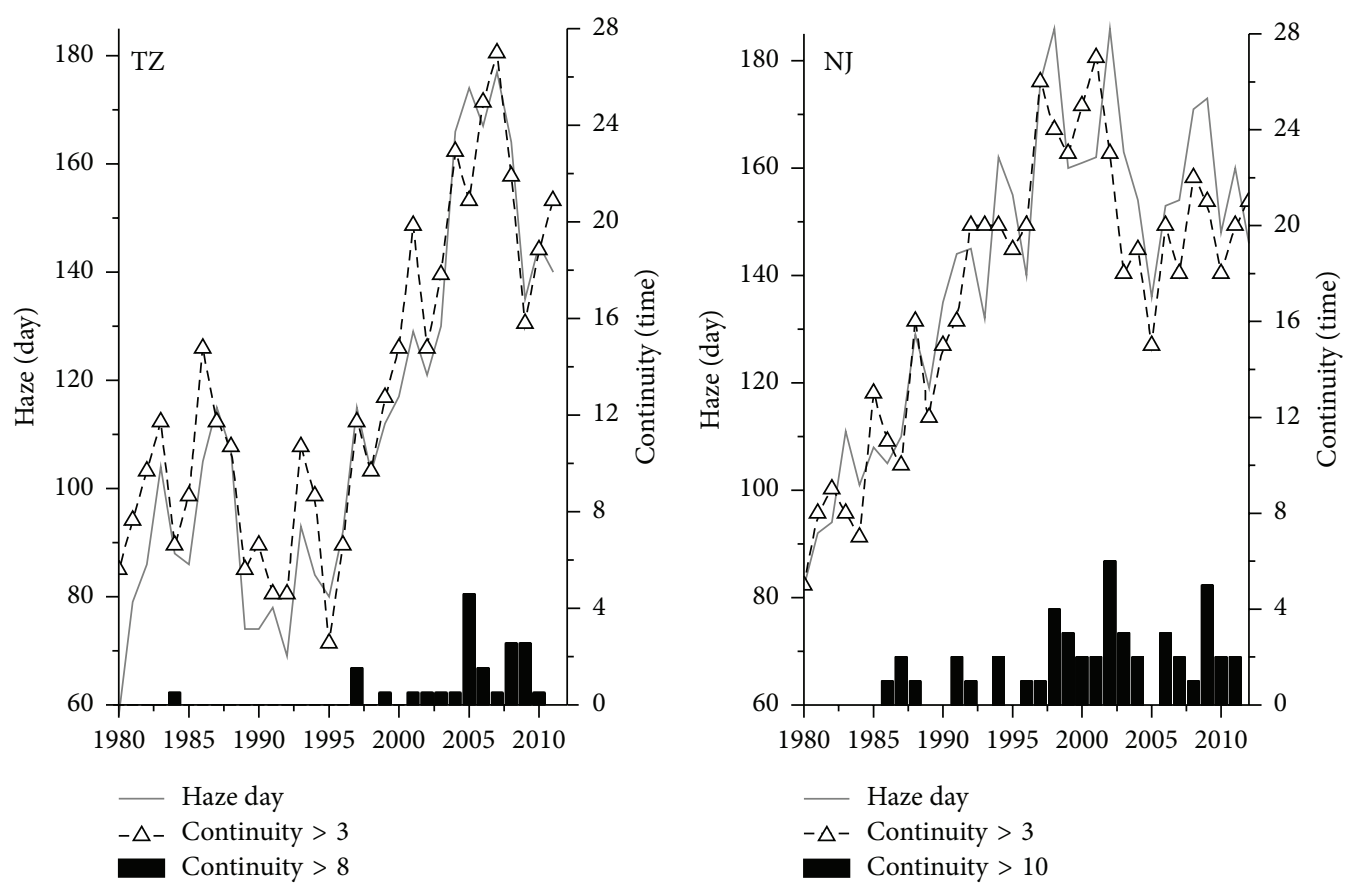

FIgURE 5: Continuous hazy day in Taizhou and Nanjing.
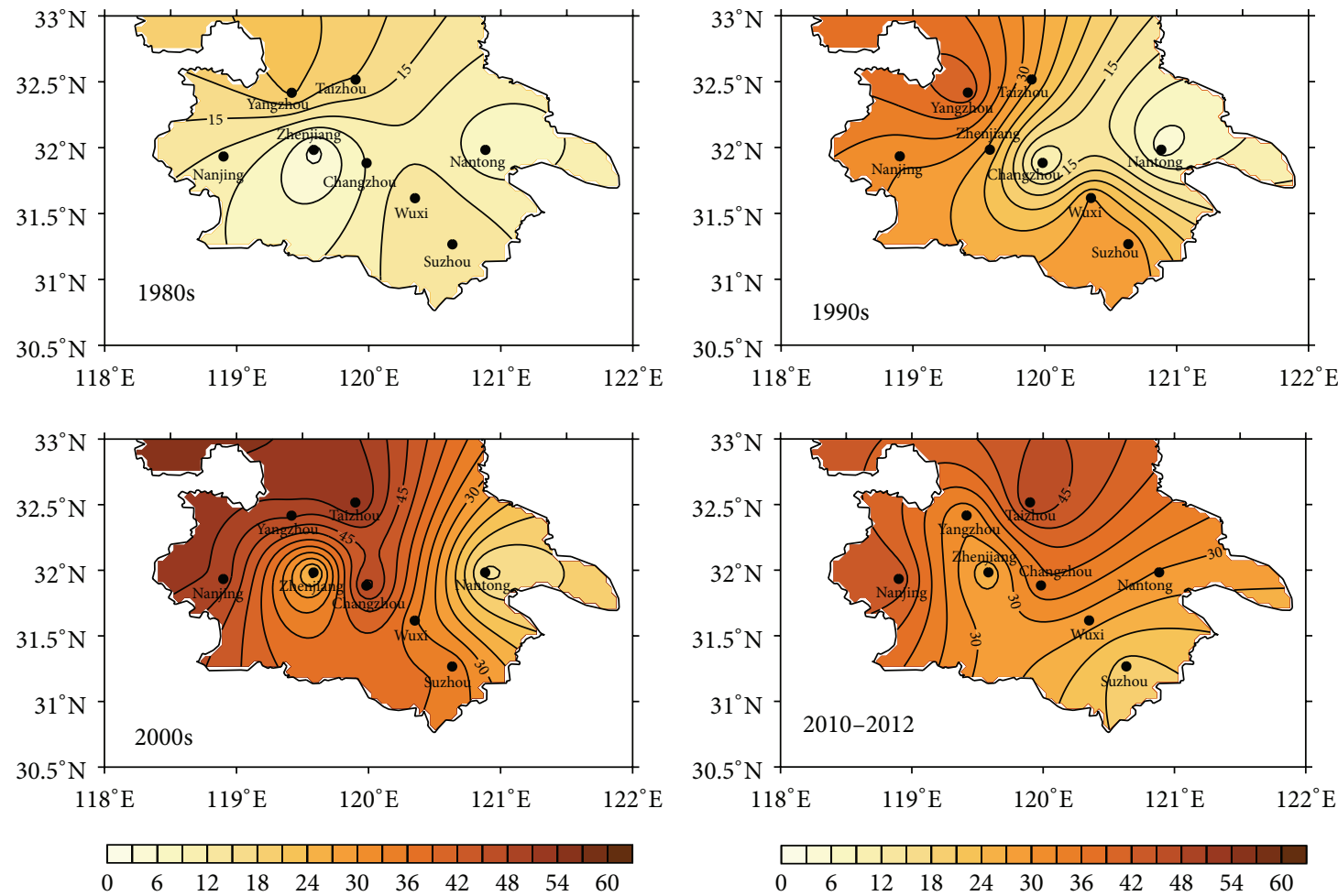

FIGURE 6: Space-time distribution of continuous hazy day south of the Huaihe River (yearly average).

\section{Factors Affecting the Variation in the Number of Hazy Days}

The total developed areas in the cities of the province increased by a factor of 3.15 from 1994 to the end of 2011 (Figure 8).
The total amount of industrial emissions in the province increased by a factor of 2.74 between 1999 and the end of 2010. By the end of 2011, the total amount of coal combustion and the number of private cars in the province increased by factors of 4.6 and 12.45 , respectively, compared to the 


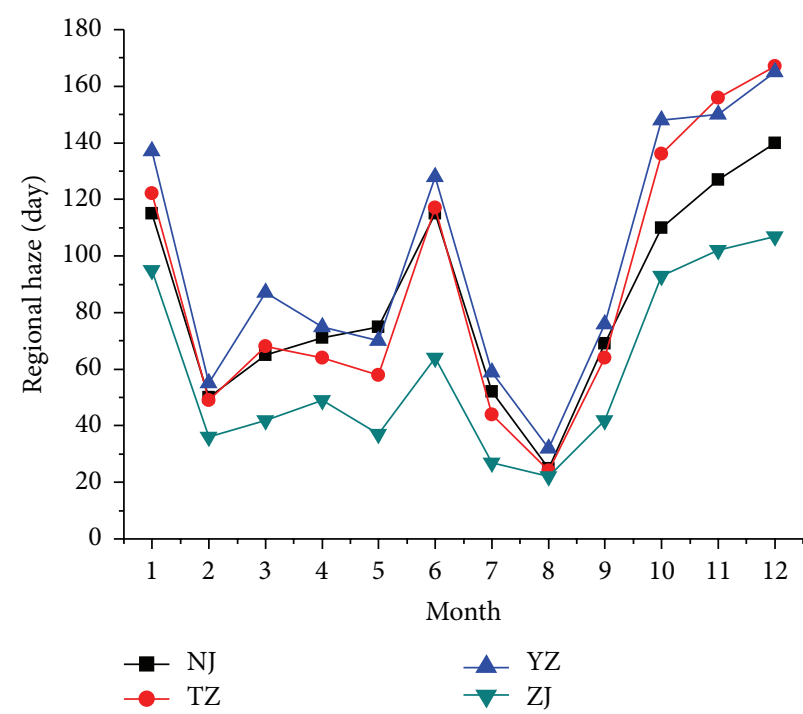

(a)

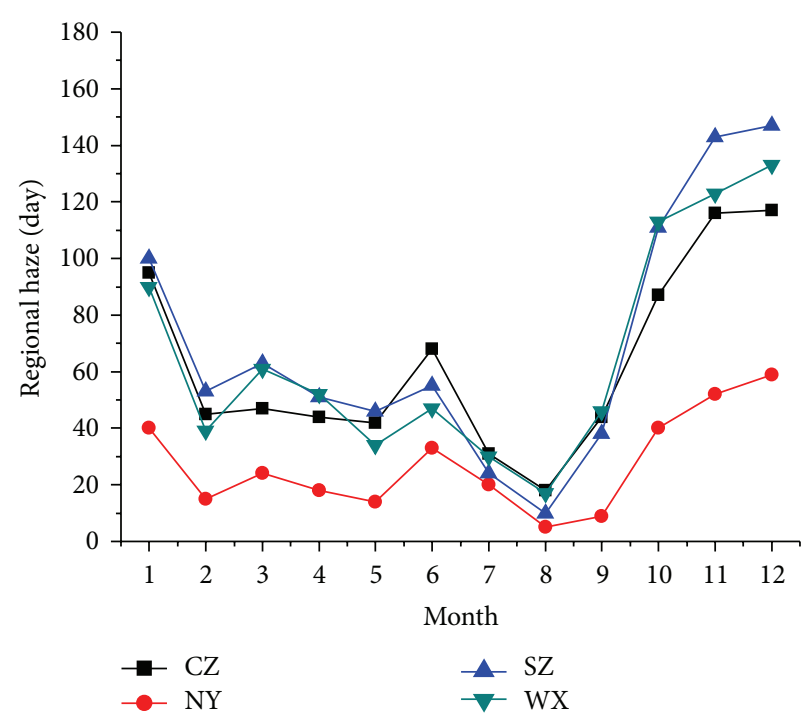

(b)

Figure 7: Monthly changes of regional hazy day south of the Huaihe River (summer of 33 years).

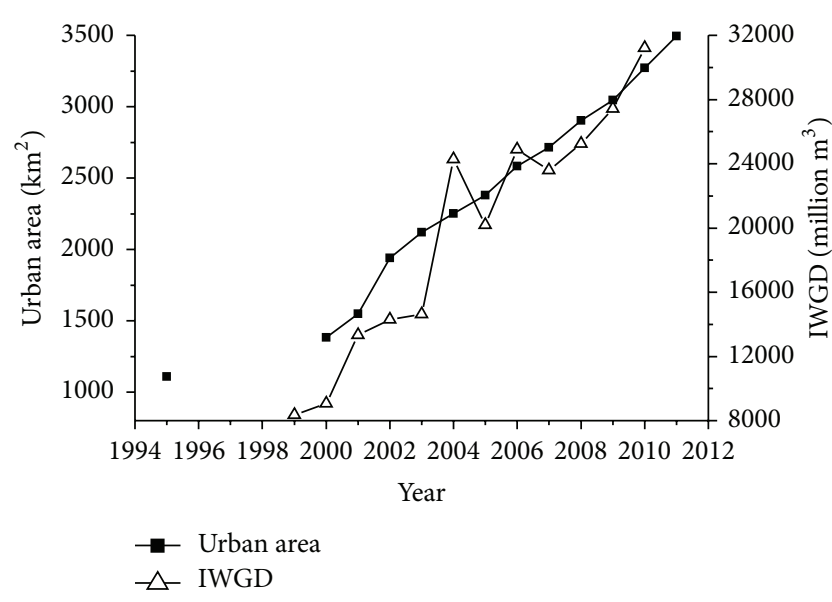

(a)

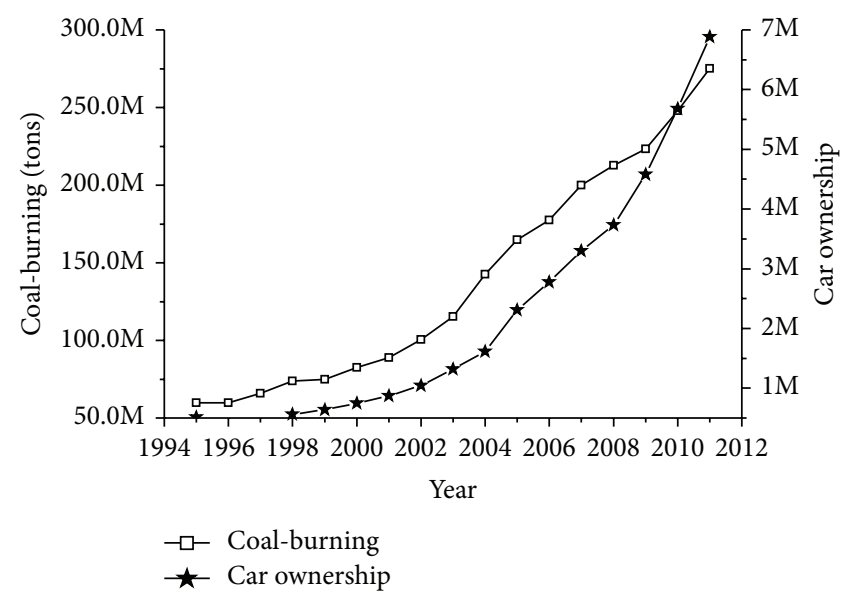

(b)

Figure 8: The socioeconomic indicators in Jiangsu Province ((a): urban area and industrial waste gas discharge; (b): coal-burning and car ownership).

1995 values; these factors are positively correlated with the interannual and decadal increments in the number of hazy days in Jiangsu Province.

In addition to the four economic indicators mentioned above, since the 1980s the annual-averaged amount of pollutants (including $\mathrm{NO}_{x}, \mathrm{PM}_{10}$, and $\mathrm{SO}_{2}$ ) emitted had also been constantly increasing in Jiangsu Province and surrounding areas (Figure 9). (1) Since the 1980s, the spatial distribution of these three pollutants had been higher in southern Jiangsu and along the Yangtze River than in northern Jiangsu and along the coast; therefore, the number of hazy days in southern Jiangsu and along the Yangtze River was higher than in northern Jiangsu and along the coast most of the time. (2) Since 2000, the increment in the amount of pollutants emitted had been relatively significant in northern Jiangsu and along the coast; as a result, the number of hazy days had increased significantly in northern Jiangsu and along the coast during the last several years of our study period. (3) The areas with high concentrations of pollutants south of the Huaihe River had been connected into one big region, and its range was gradually expanding; therefore, the increase in the number of continuous and regional hazes in this region was significant.

Haze forms on the basis of many meteorological and environmental factors but particularly on the basis of two meteorological factors: temperature and relatively humidity. Previous studies [12, 41, 42] indicated that changes in meteorological conditions, regional urbanization, and land use can cause temperature to increase and relative humidity to decrease, which resulted in more frequent hazy days. Li et al. [43] analyzed the effects of city and economic development 


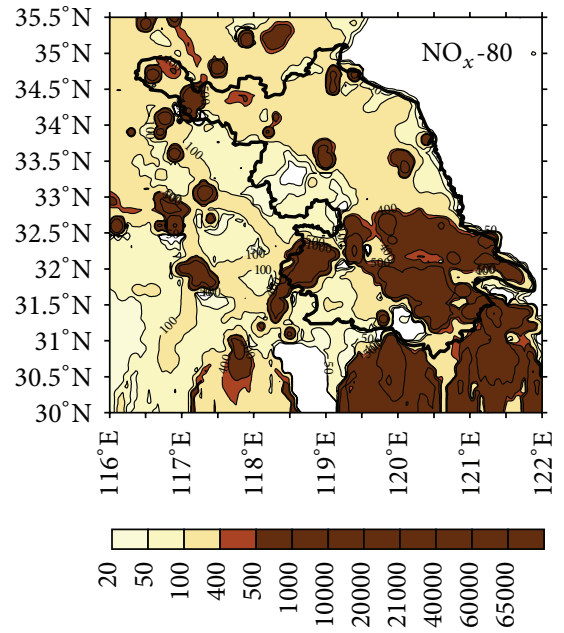

Unit (ton)

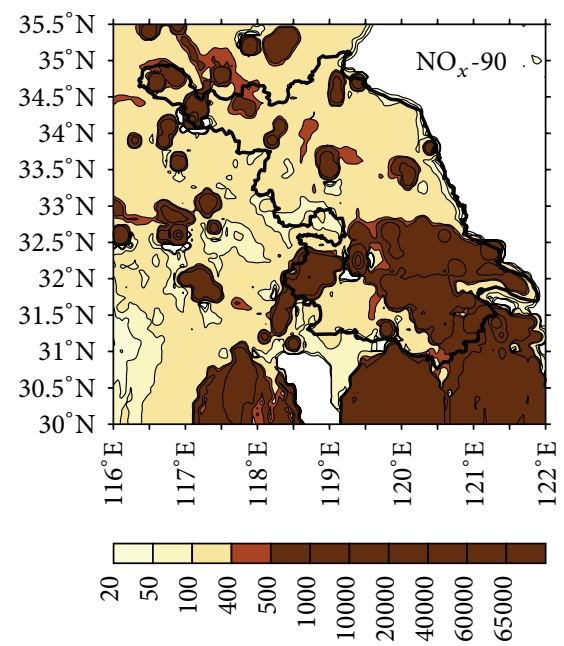

Unit (ton)

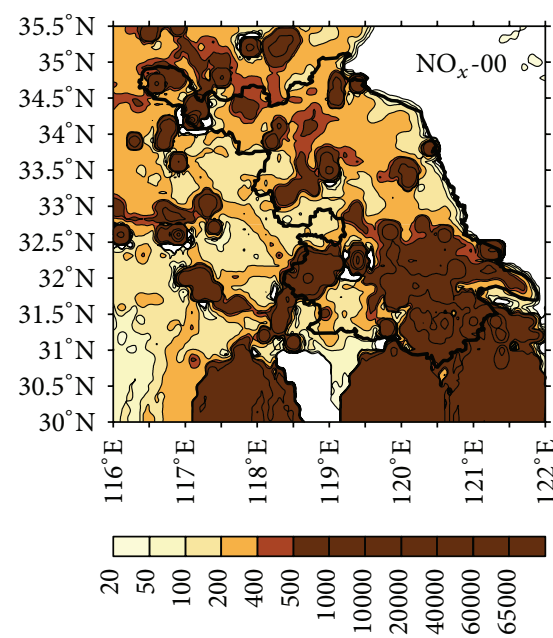

Unit (ton)

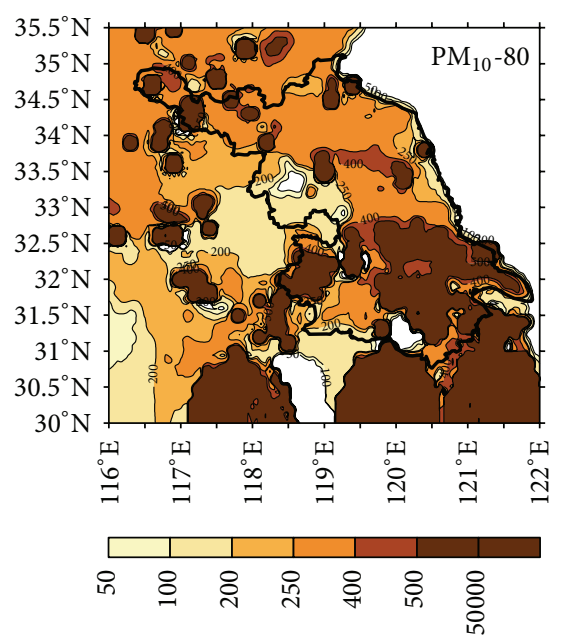

Unit (ton)

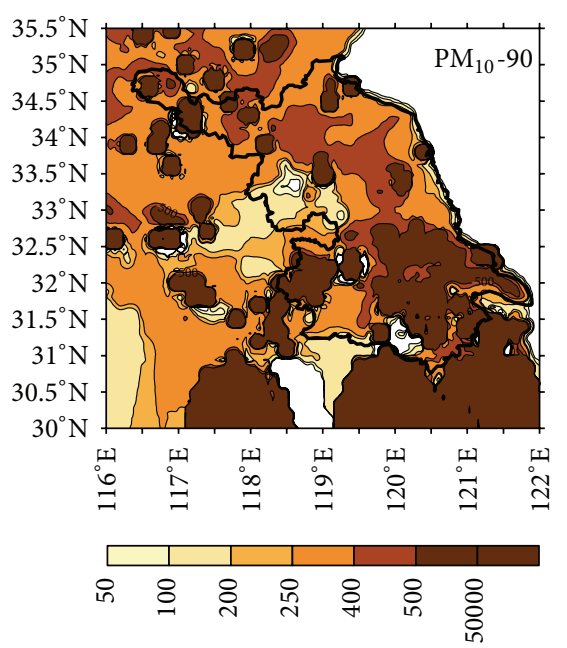

Unit (ton)

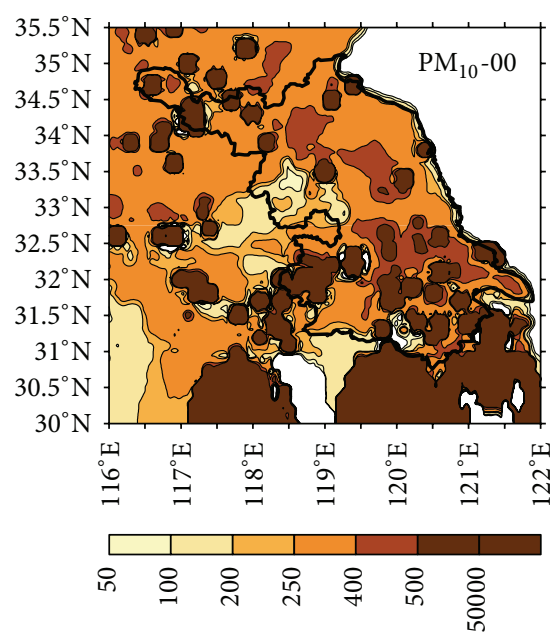

Unit (ton)

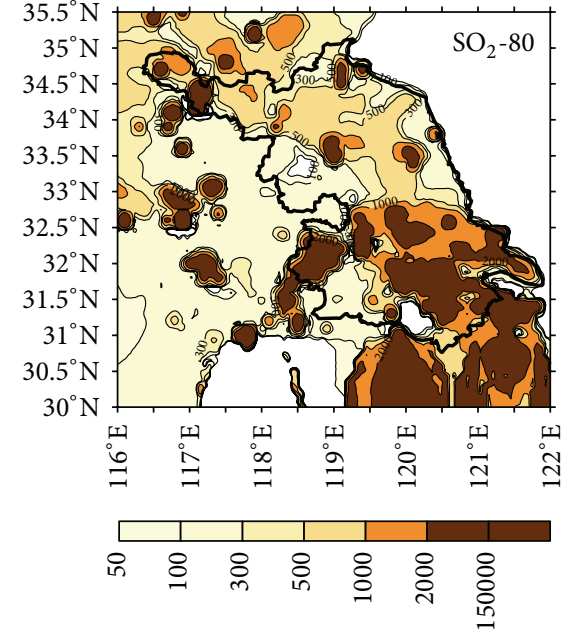

Unit (ton)

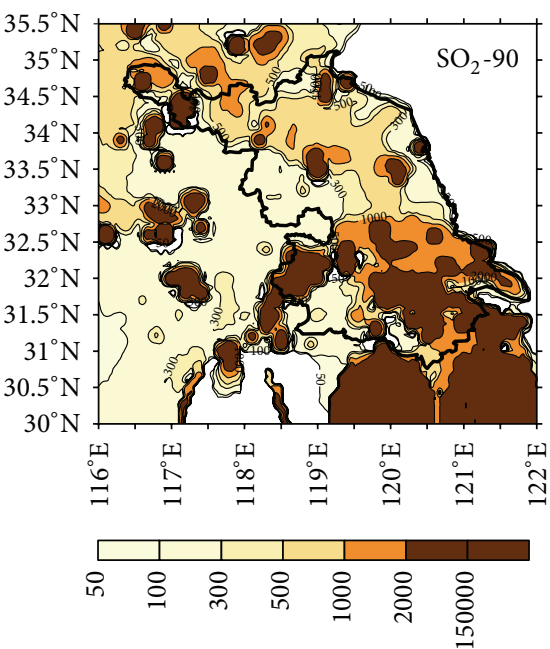

Unit (ton)

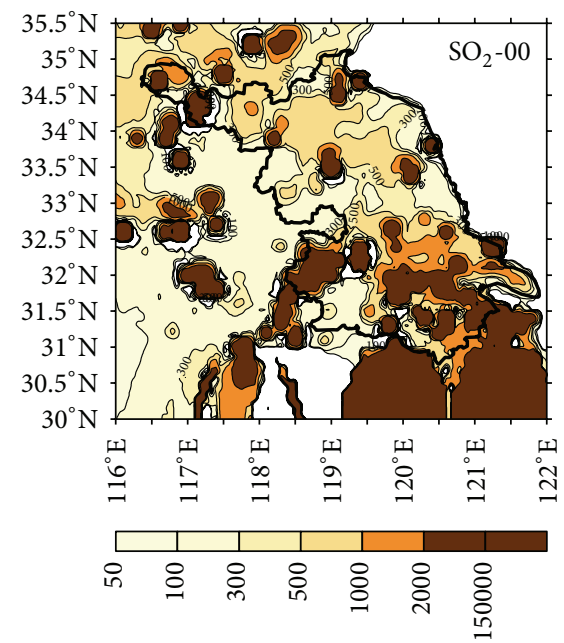

Unit (ton)

FIGURE 9: Decadal changes of $\mathrm{NO}_{x}, \mathrm{PM}_{10}$, and $\mathrm{SO}_{2}$ emissions in Jiangsu Province and neighboring areas (yearly average). 

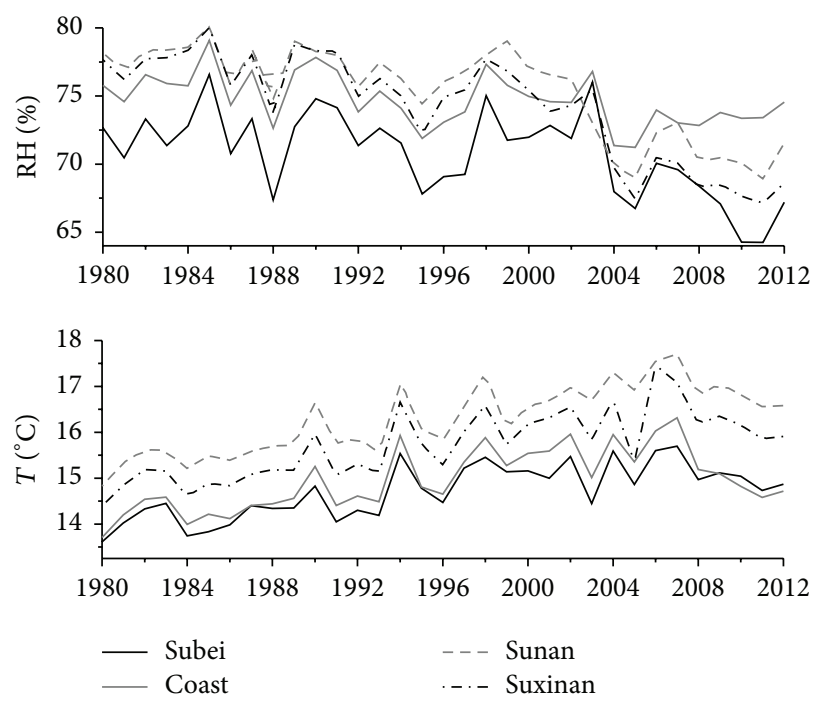

FIgURe 10: Average annual temperature and relative humidity in Jiangsu Province.

TABLE 4: Regional characteristics of continuous hazy day.

\begin{tabular}{lccc}
\hline $\begin{array}{l}\text { Continuous } \\
\text { hazy day/d }\end{array}$ & Times & Date & $\begin{array}{c}\text { Station } \\
\text { number }\end{array}$ \\
\hline 3 & 71 & & \\
4 & 31 & & \\
5 & 11 & $1994 / 7 / 24-29$ & 6 \\
& & $2002 / 2 / 3-8$ & 7 \\
6 & 3 & $2004 / 12 / 12-17$ & 8 \\
& & $1990 / 12 / 04-10$ & 7 \\
& & $1992 / 1 / 22-28$ & 8 \\
7 & 4 & $2003 / 1 / 8-14$ & 8 \\
& & $2008 / 1 / 4-10$ & 8 \\
8 & 1 & $2006 / 12 / 20-27$ & 7 \\
9 & 1 & $2006 / 10 / 28-11 / 05$ & 8 \\
10 & 2 & $1999 / 12 / 26-2000 / 01 / 04$ & 8 \\
11 & 1 & $2001 / 11 / 16-25$ & 8 \\
& & $2006 / 10 / 04-14$ & 8 \\
\hline
\end{tabular}

in China after 1978 on fog. They found that as the urban developed areas expanded, the amount of vegetation coverage in the city gradually declined, as did relative humidity. The urban heat island effect became more obvious, and the number of hazy days exhibited a downward trend in the cities. Therefore, the expansion of urban areas and the increase in industrial emissions and coal combustion caused the number of hazy days to increase in these cities.

From 1980 to 2012, there were considerable changes in the annual-averaged temperature and relative humidity in the four regions of Jiangsu Province (Figure 10). From 1980 to 2006, the temperature increased significantly, and the relative humidity exhibited a downward trend. During this period, the number of hazy days in the four regions of the province exhibited an upward trend. From 2006 to 2012, the temperature in these four regions again exhibited a downward trend, and the relative humidity remained essentially unchanged in the other regions, except for the three cities in northern Jiangsu; as a result, the number of hazy days in southern and southwestern Jiangsu also decreased. In addition, because the relative humidity had been much lower in northern, southwestern, and southern Jiangsu than in the coastal area since 2000 and the temperature had been much higher in southern and southwestern Jiangsu than in the coastal cities, the number of hazy days had been greater in the inland regions than along the coast.

The above analysis has shown that, alongside city and economic development, the urban developed area expanded and the amount of industrial emissions and automobile exhaust increased, causing changes in the meteorological environment in these cities and surrounding areas. The temperature slowly increased and the relative humidity decreased, creating an urban heat island effect and leading to the dry island effect. The conditions for fog formation gradually weakened. In addition, increments in the amount of pollutants emitted enhanced the conditions for the formation and maintenance of haze; therefore, the increase in the numbers of continuous, regional, and continuous regional hazy days was also obvious.

\section{Conclusions}

(1) From 1980 to 2012, the number of hazy days in Jiangsu Province exhibited an upward trend, and the increments in the numbers of heavy and moderate hazy days were significant. The number of hazy days increased significantly in northern Jiangsu and in the coastal cities. The number of hazy days was the highest in fall and winter and the lowest in summer. The haze in fall and winter generally occurred inland and was relatively rare along the coast. The number of hazy days was the greatest between October and January 
and relatively high in June, except in the three cities in the south.

(2) The number of hazy days was relatively uniform across the province in the 1980s, and it increased in southern and southwestern Jiangsu during the 1990s. In the 2000 s, the number of hazy days began to increase between the Yangtze River and the Huaihe River and in northern Jiangsu; from 2010 to 2012, the number of hazy days increased significantly in northern Jiangsu and decreased slightly in southern Jiangsu. The length of haze event and the number of hazy days in regional haze changed synchronously with the number of hazy days; in the cities with more hazy days, the number of continuous hazy days was also relatively high.

(3) The urban developed area expanded slightly every year and the amount of pollutants resulting from industrial emissions and automotive exhaust increased annually, which caused the regional temperature to increase and relative humidity to decrease. Along with the increase in the amount of pollutants, the conditions for the formation and maintenance of hazy days were strengthened, and the frequency of continuous, regional, and continuous regional hazy days also increased relatively significantly.

\section{Competing Interests}

The authors declare that there are no competing interests regarding the publication of this paper.

\section{Acknowledgments}

Funding for this work was jointly provided by the Natural Science Foundation of Jiangsu Province (Grant no. BK20130111), National Key Technology Support Program (2014BAC22B04), the National Natural Science Foundation of China (41575135, 91544229, and 91544231), and the Key Projects of Jiangsu Meteorological Bureau (Grant no. KZ201405).

\section{References}

[1] China Meteorological Administration, The Ground Meteorological Observation Specification, Meteorological Publishing House, Beijing, China, 2003.

[2] China Meteorological Administration, Haze Level of Observation and Prediction, Meteorological Publishing House, Beijing, China, 2003.

[3] X. Y. Zhang, J. Y. Sun, Y. Q. Wang et al., "Factors contributing to haze and fog in China," Chinese Science Bulletin, vol. 58, no. 13, pp. 1178-1187, 2013 (Chinese).

[4] Y. Xingna, L. Xinmei, D. Zengrandeng et al., "Optical properties of aerosol during haze-fog episodes in Beijing," Environmental Science, vol. 33, no. 4, pp. 1057-1062, 2012 (Chinese).

[5] X.-J. Zhao, W.-W. Pu, W. Meng, Z.-Q. Ma, F. Dong, and D. He, "PM2.5 pollution and aerosol optical properties in fog and haze days during autumn and winter in Beijing area," Environmental Science, vol. 34, no. 2, pp. 416-423, 2013 (Chinese).
[6] M. Yongliang, T. Jihua, H. Kebin et al., "Characteristics of volatile organic compounds during haze episode in Foshan City," Environmental Science, vol. 32, no. 12, pp. 3549-3554, 2011 (Chinese).

[7] R.-R. Qian, J.-M. Yan, S.-P. Wu, and X.-H. Wang, "Characteristics and sources of PM 10-bound PAHs during haze period in winter-spring of Xiamen," Environmental Science, vol. 33, no. 9, pp. 2939-2945, 2012 (Chinese).

[8] H. Yimin, L. Zirui, H. Chen et al., "Characteristics of mass size distributions of water-soluble inorganic ions during summer and winter haze days of Beijing," Environmental Science, vol. 34, no. 4, pp. 1236-1244, 2013 (Chinese).

[9] J.-H. Tan, J.-P. Zhao, J.-C. Duan, Y.-L. Ma, K.-B. He, and F.-M. Yang, "Pollution characteristics of organic acids in atmospheric particles during haze periods in autumn in Guangzhou," Environmental Science, vol. 34, no. 5, pp. 1982-1987, 2013 (Chinese).

[10] J. Tao, F.-H. Chai, J. Gao, J.-J. Cao, S.-X. Liu, and R.-J. Zhang, "Characterization of chemical compositions in PM2.5 and its impact on hazy weather during 16th Asian Games in Guangzhou," Environmental Science, vol. 34, no. 2, pp. 309-415, 2013 (Chinese).

[11] Y. Yongwen, C. Jinping, D. Yusen et al., "Correlation analysis between the PM2.5, PM10 which were taken in the hazy day and the number of outpatient about breathing sections, breathing sections of pediatrics in Shanghai," Journal of Environment Science, vol. 32, no. 7, pp. 1894-1898, 2011 (Chinese).

[12] G. Gao, "The climatic characteristics and change of haze days over China during 1961-2005," Acta Geographica Sinica, vol. 63, no. 7, pp. 761-768, 2008.

[13] S. Yu, M. Zhenfeng, N. Tao et al., "Characteristics of climate change with respect to fog days and haze days in China in the past 40 years," Climatic and Environmental Research, vol. 18, no. 3, pp. 397-406, 2013 (Chinese).

[14] W. Dui, "Hazy weather research in China in the last decade: a review," Acta Scientiae Circumstantiae, vol. 32, no. 2, pp. 257269, 2012 (Chinese).

[15] Y. L. Dai, J. Tao, Z. J. Lin, S. D. Xie, J. J. Cao, and R. J. Zhang, "Characteristics of haze and its impact factors in four megacities in China during 2006-2009," Environmental Science, vol. 34, no. 8, pp. 2925-2932, 2006 (Chinese).

[16] H. Che, X. Zhang, Y. Li, Z. Zhou, J. J. Qu, and X. Hao, "Haze trends over the capital cities of 31 provinces in China, 19812005," Theoretical and Applied Climatology, vol. 97, no. 3-4, pp. 235-242, 2009.

[17] N. E. Westcott and D. A. R. Kristovich, "A climatology and case study of continental cold season dense fog associated with low clouds," Journal of Applied Meteorology and Climatology, vol. 48, no. 11, pp. 2201-2214, 2009.

[18] S. M. Vicente-Serrano, J. I. López-Moreno, M. I. VegaRodríguez, S. Beguería, and J. M. Cuadrat, "Comparison of regression techniques for mapping fog frequency: application to the Aragón region (northeast Spain)," International Journal of Climatology, vol. 30, no. 6, pp. 935-945, 2010.

[19] H. Tokinaga and S.-P. Xie, "Ocean tidal cooling effect on summer sea fog over the Okhotsk Sea," Journal of Geophysical Research D: Atmospheres, vol. 114, no. 14, Article ID D14102, 2009.

[20] Z. Ningfang, L. Feng, R. Xiaoqin et al., "Study on haze weather in China during winter-time of 2006," Meteorological Monthly, vol. 34, no. 6, pp. 81-88, 2008 (Chinese).

[21] S.-U. Park, I.-H. Lee, and S. J. Joo, "Spatial and temporal distributions of aerosol concentrations and depositions in Asia 
during the year 2010," Science of The Total Environment, vol. 542, pp. 210-222, 2016.

[22] G. Wu, Z. Li, C. Fu et al., "Advances in studying interactions between aerosols and monsoon in China," Science China Earth Sciences, vol. 59, no. 1, pp. 1-16, 2016.

[23] Z. Yin, H. Wang, and W. Guo, "Climatic change features of fog and haze in winter over North China and Huang-Huai Area," Science China Earth Sciences, vol. 58, no. 8, pp. 1370-1376, 2015.

[24] J. Shi, L. Cui, Q. He, and L. Sun, "The changes and causes of fog and haze days in eastern China," Acta Geographica Sinica, vol. 65, no. 5, pp. 533-542, 2010 (Chinese).

[25] Y. Niu, J. Gu, J. Pu, W. Li, and J. Wu, "The long-term variation of haze weather in urban areas of Zhejiang," Journal of Tropical Meteorology, vol. 26, no. 6, pp. 807-812, 2010 (Chinese).

[26] Z. Pengbo, J. Aijun, S. Jiali et al., "Decadal change characteristics of autumn haze days in jiangsu province and its influential factors," Progressus Inquisitiones de Mutatione Climatis, vol. 8, no. 3, pp. 205-212, 2012 (Chinese).

[27] J. Song, T. Cheng, Z. Xie et al., "Impact on spatio-temporal variation of fog and haze days due to rapid urbanization in Jiangsu," Journal of the Meteorological Sciences, vol. 32, no. 2, pp. 275-281, 2012 (Chinese).

[28] S. Cune, Z. Wuquan, Y. Jun et al., "Characteristics of PM10 pollution at four provincial cities in yangtze river delta district," Plateau Meteorology, vol. 27, no. 2, pp. 408-414, 2008 (Chinese).

[29] Z. Cheng, S. Wang, J. Jiang et al., "Long-term trend of haze pollution and impact of particulate matter in the Yangtze River Delta, China," Environmental Pollution, vol. 182, pp. 101-110, 2013.

[30] L. Tang, H. Yu, A. Ding et al., "Regional contribution to PM1 pollution during winter haze in Yangtze River Delta, China," Science of The Total Environment, vol. 541, pp. 161-166, 2016.

[31] M. Wang, C. Cao, G. Li, and R. P. Singh, "Analysis of a severe prolonged regional haze episode in the Yangtze River Delta, China," Atmospheric Environment, vol. 102, pp. 112-121, 2015.

[32] Y. Zhang, Q. Zhang, C. Leng et al., "Evolution of aerosol vertical distribution during particulate pollution events in Shanghai," Journal of Meteorological Research, vol. 29, no. 3, pp. 385-399, 2015.

[33] Y. W. Zhang, X. Y. Zhang, Y. M. Zhang et al., "Significant concentration changes of chemical components of PM1 in the Yangtze River Delta area of China and the implications for the formation mechanism of heavy haze-fog pollution," Science of the Total Environment, vol. 538, pp. 7-15, 2015.

[34] P. Aoda, F. Sudan, and C. Haishan, "Characteristic of extreme climate change over Jiangsu Province in the last 45 a," Scientia Meteorologica Sinica, vol. 30, no. 1, pp. 87-92, 2010 (Chinese).

[35] A. Jiang, Y. Xiang, H. Peng, and B. Wang, "The analyse of jiangsu climate variety in forty years," Scientia Meteorologica Sinica, vol. 26, no. 5, pp. 525-529, 2006 (Chinese).

[36] M. Yuqing, S. Yan, J. Aijun et al., "An experiment al study of haze predi ct ion method in Nanjing," Clim at ic and Environment al Research, vol. 16, no. 3, pp. 273-279, 2011 (Chinese).

[37] Y.-Q. Tong, Y. Yin, L. Qian, and J.-L. An, "Analysis of the characteristics of hazy phenomena in Nanjing area," China Environmental Science, vol. 27, no. 5, pp. 584-588, 2007 (Chinese).

[38] D. Wu, "Discuss ion on the distinction between haze and fog and analysis and processing of data," Environmental Chemistry, vol. 27, no. 3, pp. 327-330, 2008 (Chinese).

[39] D. Wu, "A discussion on difference between haze and fog and warning of ash haze weather," Meteorological Monthly, vol. 31, no. 4, pp. 3-7, 2005 (Chinese).
[40] Z. Zhou, Y. Zhu, and X. Ju, "Heavy fog events and climate characteristics of the Yangtze river delta region," Progress in Natural Science, vol. 17, no. 1, pp. 66-71, 2007 (Chinese).

[41] R. Vautard, P. Yiou, and G. J. Van Oldenborgh, "Decline of fog, mist and haze in Europe over the past 30 years," Nature Geoscience, vol. 2, no. 2, pp. 115-119, 2009.

[42] Y.-J. Yang, B.-W. Wu, C.-E. Shi et al., "Impacts of Urbanization and Station-relocation on Surface Air Temperature Series in Anhui Province, China," Pure and Applied Geophysics, vol. 170, no. 11, pp. 1969-1983, 2013.

[43] Z.-H. Li, J. Yang, C.-E. Shi, and M.-J. Pu, "Urbanization effects on fog in China: field research and modeling," Pure and Applied Geophysics, vol. 169, no. 5-6, pp. 927-939, 2012. 

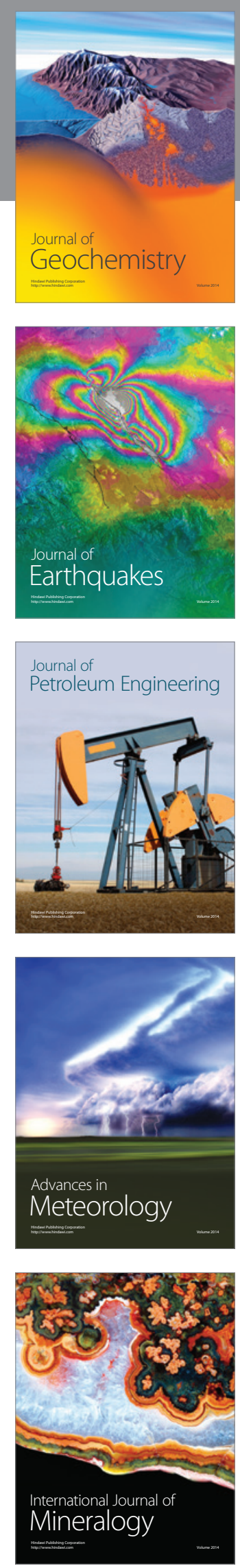
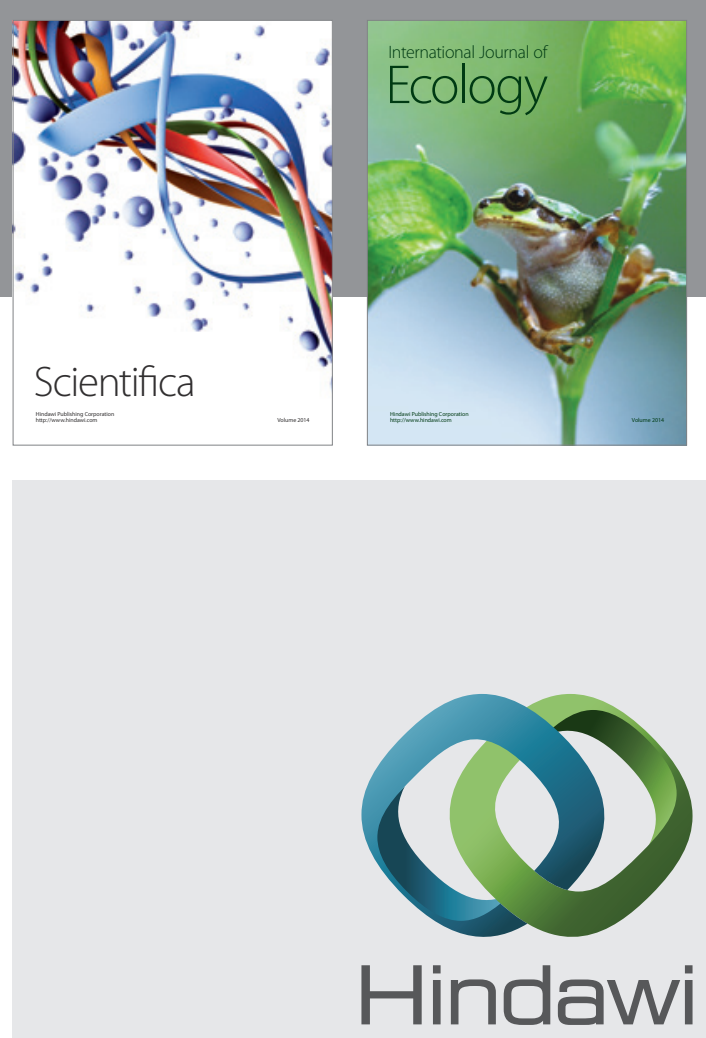

Submit your manuscripts at

http://www.hindawi.com
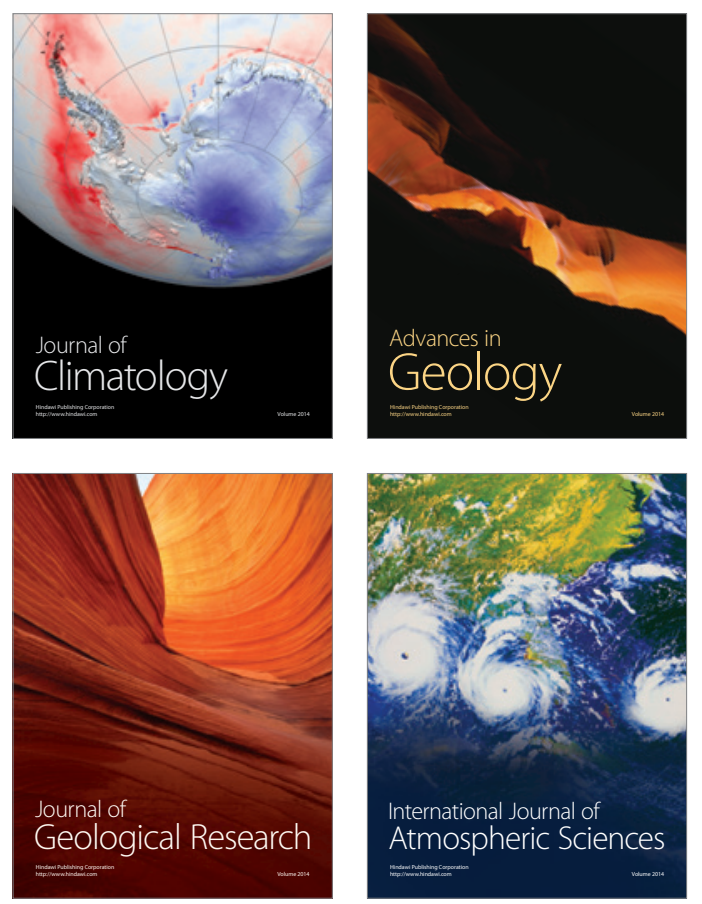

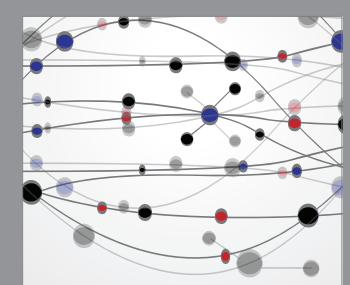

The Scientific

\section{World Journal}
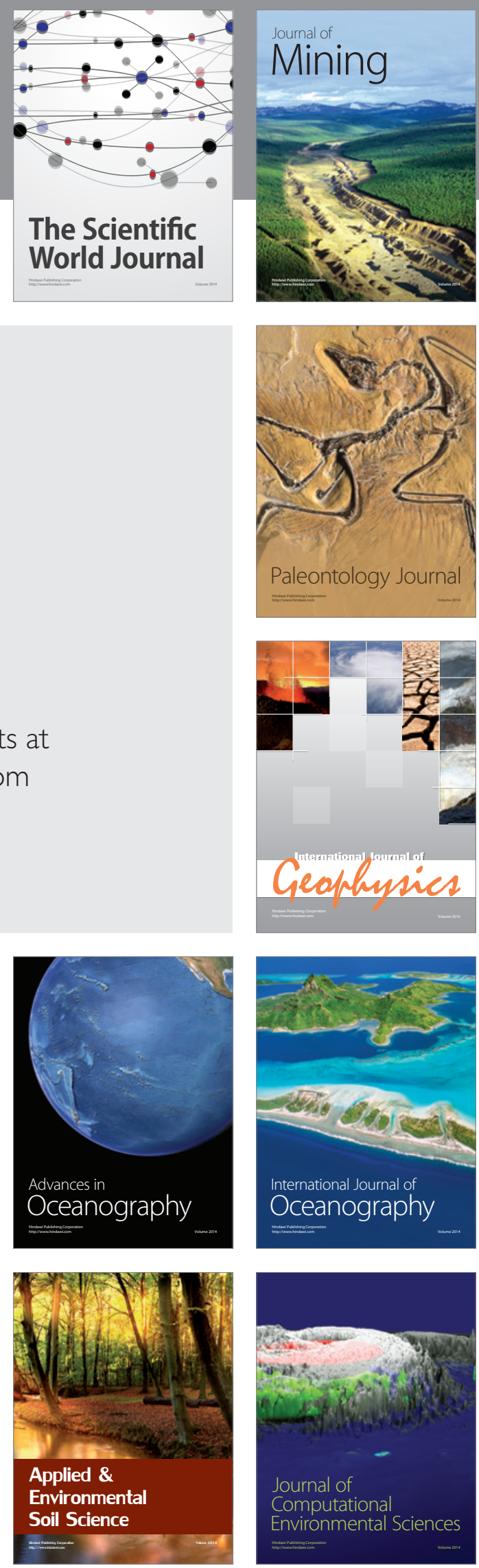